\title{
Efeitos da racionalidade neoliberal nos discursos sobre inclusão: o silêncio docente
}

\section{Effects of neoliberal rationality in speeches on}

inclusion: the teacher's silence

Leandra Boer Possa*

Universidade Federal de Santa Maria

Maria Inês Naujorks**

Universidade Federal de Santa Maria

Resumo Este texto, tomando a Política Nacional de Educação Especial na Perspectiva da Educação Inclusiva e os programas que acolhem a formação de professores para a diversidade/inclusão, coloca em movimento analítico os efeitos discursivos destes documentos. Sem a pretensão de fazer uma análise exaustiva, busca-se problematizar o efeito do silêncio docente que esta política neoliberal vem produzindo sobre os professores que atuam nos sistemas de educação municipal e estadual da região de Santa Maria. Utilizase nesse empreendimento a ferramenta conceitual-metodológica da governamentalidade para pensar que os discursos da inclusão têm capturado e subjetivado os professores, pois diante da irredutibilidade dessa rede discursiva o silêncio é um efeito de produção, consumo do princípio da inclusão e do empreendimento de si.

PALAVRAS-CHAVE: Subjetivação docente, Neoliberalismo, Inclusão.

Abstract This text, which makes use of the National Policy on Special Education in the Perspective of Inclusive Education and the programs that embrace the training of teachers for diversity/ inclusion, puts the discursive effects of these documents in analytic sets. Without attempting at doing an exhaustive analysis, this study aims at problematizing the effect of teacher's silence that the neoliberal policy has been producing on teachers who work in municipal and state education systems in Santa Maria area. The conceptual and methodological tool of governmentality is used in this enterprise in order to think that the discourses of inclusion have convinced and subjectivized teachers, because in the face of the irreducibility of this discursive network the silence is an effect of the production and consumption of the principle of inclusion and enterprise itself.

KEYWORDS: Teacher subjectivity, Neoliberalism, Inclusion. 


\section{Apresentação}

Vivemos em um tempo de transformações vertiginosas e nesse tempo as funções do professor apresentam-se para além do ato de ensinar, exigindo-lhes cada vez maiores e mais complexas responsabilidades. Circulando nas escolas das redes municipal e estadual do município de Santa Maria (RS) e também participando de eventos científicos da área da Educação Especial, vimos percebendo nos últimos anos que os docentes já não utilizam mais determinadas formas de desabafo que expressavam o desconforto em relação à inclusão escolar de alunos com deficiência. Notadamente, a fragilidade dos processos formativos, as condições de trabalho, a falta de recursos materiais, entre outros. Algumas pesquisas, dentre elas as de Naujorks (2006) e Possa (2007), apontavam que, nos sistemas de ensino, os professores da Educação Básica clamavam por mais formação e preparo para atuarem nesse "novo" modelo educacional formal que toma como princípio a educação inclusiva, a educação para todos.

A partir dessas constatações e levando em conta alguns marcos instituídos, principalmente na área da Educação Especial, de 2008 para cá, começamos a suspeitar que os modos de dizer sobre a inclusão estão se modificando e que esses marcos vêm provocado efeitos importantes que precisam ser problematizados. Um dos efeitos que tem ocupado nossas discussões é o que estamos chamando de silêncio docente.

Este termo, silêncio docente, foi construído por nós a partir do estudo das relações de força que, para Foucault, constituem subjetividades numa vontade de saber na racionalidade moderna (FOUCAULT, 1988) e da percepção de que, em nosso tempo, a inclusão se constituiu em um modo de dizer sobre a educação, um modo de nominá-la que exerce uma forma de controle no vocabulário autorizado aos professores. Ou seja, o imperativo autorizado torna a problemática da inclusão, até a pouco debatida e questionada na escola e no sistema educacional, aceitável e tecnicamente útil. Exerceu-se um modo de administração e não de julgamento às angustias, aos desabafos sobre a falta de preparo ou sobre a falta de recursos. Foi pela palavra e pela administração de estratégicas de governo dos professores que se reorganizaram e modificaram suas questões em um curso esperado. Organizaramse, administraram-se os desabafos numa rede de discurso regulada, limitada e codificada. Não foi com um mecanismo negativo ou de rejeição dos desabafos e de expressões de desconfortos que se operou em relação aos professores e ao sistema educacional; tratou-se de colocar em funcionamento uma rede sutil de discursos, saberes e poderes que multiplicaram controles por toda a extensão da sociedade, que operaram o silenciamento, pois a inclusão, como imperativo, constitui-se em uma forma codificada que se impõe a todo o modo de falar dos professores.

Este efeito de silêncio docente que estamos percebendo tem nos levado a perguntar: o que vem movimentando subjetivamente os professores, nestes últimos anos, para que silenciassem? Como, a partir da política neoliberal e dos discursos sobre a inclusão, vem se produzindo este efeito? Seria possível apontar alguns acontecimentos que, em rede, produz esse efeito nos docentes? 
Como se tornam produtivos estes acontecimentos para operarem nos processos de subjetivação dos professores?

Não temos a pretensão de responder a essas questões. Temos sim, como objetivo, neste artigo, colocar essas questões em movimento analítico tendo como objetos de relação a Política Nacional de Educação Especial na Perspectiva da Educação Inclusiva de 2008 e também os programas que acolhem a formação de professores para a diversidade/inclusão que podem ser acessados em seus objetivos no site do Ministério da Educação (MEG).

Para tal empreendimento analítico, iremos utilizar a ferramenta conceitual-metodológica da noção de governamentalidade que, a partir de Michel Foucault, coloca em funcionamento os conceitos de subjetivação e governo de si.

\section{Acontecimentos e efeitos}

Propomos, então, inicialmente, percorrer alguns acontecimentos que consideramos terem sido produtivos para operarem este efeito de silêncio docente. Todos eles são ações desenvolvidas pelo Estado através do Ministério da Educação e se caracterizam na legitimação de uma política e em programas governamentais que estão aí para dar condições de inclusão na escola, bem como de formação inicial e continuada dos professores, colocando-os como empreendedores de si.

O lançamento, em 2008, da Política Nacional de Educação Especial na Perspectiva Inclusiva, um texto elaborado por diferentes pesquisadores da área da Educação e da Educação Especial desde 2007, contituiu um grupo de trabalho para pensar as diretrizes da inclusão das pessoas deficientes no ensino comum. $\mathrm{O}$ agrupamento desses pesquisadores, de diferentes regiões do país, bem como seu reconhecimento intelectual como expertises pareceu legitimar o teor textual do documento, a verdade produzida sobre a inclusão e, portanto, o convencimento necessário para que ela se efetive.

Nesse sentido, o texto desse documento vem sendo aplicado à inclusão como regime de verdade para orientar as práticas da escola comum, o que as constitui num imperativo que coloca o financiamento de recursos físicos, didáticos e de acessibilidade junto com a formação, como caminho para esta implementação. Fica explicito que os recursos devem chegar a todas as escolas e que a formação deve atingir a todos os professores e gestores, pois a escola inclusiva configura o caminho para uma sociedade inclusiva, justa e cidadã. Nesse sentido, a formação, garantida pelo Estado, promove a aprendizagem de conhecimentos dos professores para que se construa um sistema educacional inclusivo.

A política em questão dirige, então, a partir de 2008, uma definição da inclusão e um regime de verdade que posicionam como direito humano o estar junto, criar espaços para todos, sendo necessário que a escola e seus professores assumam esse compromissos como seus. Como afirma Menezes (2011), a perspectiva da inclusão como imperativo na educação projeta subjetividades inclusivas. Para a autora, as subjetividades inclusivas se constituem a partir dos 
[...] discursos e práticas (escolares) assumidos como verdadeiros, [...] que possibilitaram a emergência de tipos específicos de subjetividades, adaptáveis ao modo de vida das sociedades contemporâneas, que eu nomeio como inclusivas. [...] Tais subjetividades são significadas por mim, entre outras características, como aquelas que, mobilizadas pelo acesso (sem restrições) e pela igualdade de oportunidades que lhes são ofertados, se sentem estimuladas (sujeitando-se) ao autoinvestimento. Esse autoinvestimento pode resultar em acúmulo de capital humano (pelo desenvolvimento de habilidades e competências, pela construção de saberes e novas aprendizagens...), o que, por sua vez, poderá resultar em uma (sensação de) maior autonomia pelos sujeitos em suas decisões e escolhas, além de maiores condições de participação nas redes de consumo. Ao experimentar a (sensação de) liberdade para fazer suas escolhas em um meio que lhe apresenta múltiplas e variadas ofertas, esse sujeito usufrui do acesso que lhe é ofertado, alimentando o ciclo da oferta e do consumo da lógica neoliberal, o que (re)compensaria os investimentos do Estado em sua educação. (MENEZES, 2011, p. 148-149)

No âmbito da sociedade neoliberal, o investimento político na inclusão a torna um produto simbólico a ser consumido graças à subjetivação de sentidos. A escola, juntamente com outras instituições, gesta redes de discursos que legitimam a inclusão, pois nessas redes se projetam e fazem circular um produto que subjetivamente se fixa a partir de acordos coletivos e de regulação da vida e das práticas.

Passamos, portanto, a consumir isto que é a inclusão e as negociações de significado que se subjetivam aqui, no caso, em cada professor/a, pois não seria suportável conviver com a incerteza de significados, como afirma Canclini, (2008, p. 64): “[...] nenhuma sociedade e nenhum grupo suportam por muito tempo a irrupção errática dos desejos, nem a conseqüente incerteza de significados. Em outras palavras, precisamos pensar, ordenar aquilo que desejamos".

Parece não ser possível sobreviver sem as formas terminais dos sentidos e significados que são oferecidas às palavras. Formas terminais que, segundo Foucault (1988), são acionadas no jogo entre o verdadeiro e o falso, que certificam e legitimam certas verdades, próprias da racionalidade neoliberal, fazendo imperar efeitos de força que fabricam condutas e sujeitos.

Por isso, a relação de saber e poder constitutiva das redes de discurso em torno da inclusão, que está na política educacional nas escolas, nas novelas, nos telejornais, nas redes sociais, na campanha da fraternidade e nos marketings de produtos, vem capturando e, por isso, subjetivando também os professores a consumir determinados padrões, normas, modos de dizer e se relacionar na escola com a inclusão. Nessa captura, cada um tem empreendido em si mesmo, através de leituras, estudos e formação, para dar sentido ao fluxo deste acontecimento que fixa o significado de um trabalho educativo orientado pela inclusão. 
No entanto, não é somente a Política Nacional de Educação Especial na Perspectiva Inclusiva que opera na produção e consumo de novos significados para a inclusão. Junto com este documento, criaram-se outras estratégias legais e políticas, sendo elas:

- O Decreto n. 6.571 de 17/09/2008 - as diretrizes do atendimento especializado com o objetivo de criar a estrutura física e pedagógica para a escola se constituir inclusiva, um financiamento feito pelo Estado que prevê, além das salas de recursos multifuncionais, os materiais didáticos, os equipamentos, a formação de gestores, professores e profissionais da escola para que esta se constitua inclusiva, a contabilização do aluno que recebe atendimento especializado com o dobro do financiamento do aluno da escola comum, hoje substituído pelo Decreto n. 7.611, de 17 de novembro de 2011, que mantém o mesmo teor.

- O programa de implementação das salas de recursos multifuncionais com materiais pedagógicos e tecnológicos que possibilitariam o atendimento de qualidade dos alunos com deficiência dentro das escolas comuns, tendo um professor especialista para contribuir com a inclusão. Essas salas, recebidas pelos sistemas de ensino municipal e estadual, tiveram seu apogeu em 2008, quando 4.300 escolas receberam os equipamentos e materiais, muito mais que nos anos anteriores, entre 2005 e 2007, em que somente 1.251 escolas haviam recebido.

- A Rede Nacional de Formação de Professores que, pela Lei n. 11.502, de julho de 2007, sob coordenação da Coordenação de Aperfeiçoamento de Pessoal de Nível Superior (Capes), assumiu a formação de professores da Escola Básica, tendo um valor alto de financiamento para programar o investimento no professor e, por conseguinte, garantir as oportunidades para que esse professor empreenda em si mesmo a partir da formação oferecida pelo Estado.

Não vamos nos deter na análise desses documentos, eles servem aqui para ilustrar o grande investimento econômico do Estado em garantir, seja através de recursos materiais, seja através da formação de professores, a negociação de sentidos e a satisfação de incertezas que, por ventura, ainda colocavam em risco o projeto inclusivo.

\section{Processos de subjetivação e o silêncio docente}

Vivemos um tempo histórico em que a racionalidade política se constitui numa "racionalidade da gestão do indivíduo" (FOUCAULT, 2010a, p. 319), ou seja, certo tipo de política que faz funcionar as instituições sociopolíticas, mas também coloca em funcionamento a conduta das pessoas a partir de um regime de verdade constituído de saberes e relações de poder. Nesse tempo, o modo como as pessoas se conduzem, como elas pensam e como elas produzem a si mesmas tem relação com um modelo de racionalidade que constitui a arte de governar do neoliberalismo.

Para buscar entender o nosso tempo, Hardt e Negri (2006) usam a metáfora Império para caracterizar uma nova ordem mundial que se movimenta 
pela ausência de fronteiras e limites territoriais; que suspende a história colocandose como inevitável e ao mesmo tempo perpetuando o estado de coisas existentes - as coisas serão hoje e sempre; e, por fim, uma ordem que funciona em todos os espaços, tempos e registros da ordem social, administrando territórios, populações, interações humanas. Como salientam os autores: "O Império não só administra um território com a sua população, mas também cria o próprio mundo que ele habita. Não apenas regula as interações humanas como procura reger diretamente a natureza humana" (HARDT; NEGRI, 2006, p. 15).

A arte de governar que opera o Império se faz produtiva porque se constitui de uma racionalidade neoliberal que tem como característica a decifração de relações de caráter econômico, mas, principalmente, porque é capaz de produzir um arranjo novo dos fenômenos sociais em geral (FONSECA, 2006, p. 159). Essa arte de governar do nosso tempo generaliza "a forma política do mercado para todo o corpo social, de modo que esta - a economia de mercado - funcionará como um princípio de inelegibilidade das relações sociais e dos comportamentos individuais" (FONSECA, 2006, p. 160).

É nessa perspectiva da noção de governamentalidade, “[...] linha de força que, em todo o ocidente, não cessou de conduzir, e há muitíssimo tempo, em direção à preeminência deste tipo de saber que se pode chamar de 'governo' sobre todos os outros" (FOUCAULT, 2010a, p. 303), que podemos entender a arte de governar, a governamentalidade como:

[...] conjunto constituído pelas instituições, procedimentos, análises e reflexões, cálculos e táticas que permitem exercer essa forma bem específica, bem complexa de poder, que tem como alvo principal a população, como forma mais importante de saber, a economia política como instrumento técnico essencial, os dispositivos de segurança. (FOUCAULT, 2010a, p. 303)

É nesse contexto que vemos a inclusão como arte de governar no neoliberalismo. A política da inclusão não tem fronteiras e se transformou em um processo inevitável. A inclusão parece ter sido descoberta como algo essencial, que esteve desde sempre aí, mas não era vista pelos homens e que agora, para não perdermos mais tempo, em essência, precisa ser projetada para sempre. Essa ordem inclusiva faz funcionar todos os espaços e tempos sociais, bem como está operando na administração de territórios, populações e interações humanas. É, portanto, a inclusão, hoje, o imperativo do Império tendo como ação incorporar, diferenciar e administrar. Segundo Hardt e Negri (2006, p. 220), “o Império não cria divisões, mas reconhece as diferenças existentes ou potenciais, festeja-as e administra-as dentro de uma economia geral de comando".

$\mathrm{Na}$ lógica da inclusão, produzem-se modos específicos de governo e uma série de saberes que operam na captura dos indivíduos e da população. Sem o limite dos territórios modernos, sem fronteiras e espaços determinados para separar, a ordem neoliberal produz um tipo de governamentalidade capaz de capturar a população como objeto a ser conduzido. A captura é operada pelo regime 
de verdade geral dos seres vivos e da espécie humana; por saberes normalizadores da ciência que representa e define o normal humano e seu contrário - o anormal - que precisa ser incluído e por isso normalizado; e também cria leis e publica a necessidade de desenvolvermos novos sentimentos e atitudes, outros modos de viver e fazer, que são possíveis de serem combinados numa sociedade da informação e comunicação, tanto nas instituições como nos meios de comunicação, nas ruas e nas praças, dando à população um modelo do que é hoje politicamente correto e inevitável, adequado e inquestionável.

Neste modelo de governamento por captura da população, é possível identificar um governo sobre todos, um governo sobre cada um e um governo sobre si mesmo, como afirma Foucault (2010). Uma autorregulação, que se constitui a partir de um modelo moral de conduta, em que o indivíduo precisa estabelecer relação consigo mesmo para se constituir em um sujeito deste tempo, politicamente correto e adequado.

Além da inclusão como aspecto da ordem neoliberal, podemos também apontar o empreendedorismo como elemento constituidor dela. Projeta-se, nessa ordem, uma programação de estratégias para que a atividade dos indivíduos e seus modos de agir se constituam em capital humano. Foucault (2008) já indicava isso quando analisava as mudanças das formas de governar que se baseavam na razão de Estado para uma razão de mercado e, junto a isso, a possibilidade de a população se integrar ao mercado e consumir.

Para Gadelha, a teoria do capital humano se constitui na identificação e desenvolvimento do conjunto de habilidades e destrezas dos indivíduos que a colocam "[...] em função do avanço do capitalismo" estas que se constituem em "valor de troca" (GADELHA apud LOPES-RUIZ, 2009, p. 175). Na teoria do capital humano,

[...] o "humano" [é] um conjunto de capacidades, destrezas e aptidões próprias dos homens, adquire valor de mercado e se apresenta como forma de capital - entendido como uma soma de valores de troca que serve de base real de uma empresa capitalista. (GADELHA apud LOPES-RUIZ, 2009, p. 175)

Se faz necessário para a produção de uma ordem neoliberal a produção de um regime de verdade e de relações sociais regidas pelo mercado e produzidas por ele ao mesmo tempo em que nelas se produz. O Estado ganha a função, nessa ordem, de financiamento, dando as condições para que a população e cada um dos indivíduos se empodere, empreendedor no mercado sendo ao mesmo tempo em que precisa ser um empreendedor de si mesmo.

Empoderar-se de condições de circulação e de inclusão no mercado constitui o objetivo que cada um e todos devemos alcançar. Nessa ordem social, exige-se a apreensão normativa e normalizadora, uma regulação e autorregulação que, ao fim e ao cabo, tem a função de proteger a si e a todos do risco, sendo necessário, para tanto, que cada um e todos sejam úteis ao mercado, incluam-se e produzam nele. 
Somos constituídos, no nosso tempo, pela govermanentalidade neoliberal, pois são o espaço e tempo das relações de força que nos constituem e, por isso, constituem-se no pano de fundo em que nossos processos de subjetivação acontecem. São o lugar e o tempo em que nos tornamos sujeitos, o lugar em que nós produzimos professores, alunos, cidadãos - enfim, esses adjetivos que estamos acostumados a ouvir e a dizer.

Entendemos que é esta captura de todos nós por uma racionalidade política que hoje vem legitimando os processos de formação docente e nossa conduta em relação à inclusão e ao empreendedorismo que fazemos em nós mesmos. A noção FOUCAULTINA da governamentalidade, no campo do entendimento ético, como um "[...] conjunto das práticas pelas quais é possível constituir, definir, organizar, instrumentalizar as estratégias que os indivíduos, em sua liberdade, podem ter uns em relações aos outros" (FOUCAULT, 2006, p. 286), vem, no nosso tempo, constituindo nossos processos de subjetivação, constituindo a nós, professores, como sujeitos inclusivos e empreendedores. Somos assujeitados por redes contínuas de vigilância e controle, subjetivando-nos a encontrar, nos espaços formativos e de atuação, meios para constituir em si e para si competências e habilidades para que possamos ser reconhecidos, adequados, produtores, consumidores e, principalmente, politicamente corretos em relação aos outros e em relação à nossa atuação.

Nesse sentido, é possível dizer que a inclusão e o empreendedorismo operam nos processos de subjetivação de todos e dos professores um efeito em que se relacionam manifestações de verdade com procedimentos e modelos de conduta, em que os indivíduos, e aqui no caso os professores, passam a ser objetos, testemunhas e agentes que projetam estes aspectos da ordem neoliberal, pois na mesma medida em que são subjetivados por ela, a colocam em movimento.

Menezes (2011) identifica esta ordem como elementos da economia política, o sentido de mínimo esforço e investimento, pois são os indivíduos em sua liberdade que assumem, como escolha e interesse, esta ordem. Assim como escolhem ser inclusivos e incluídos; empoderados e empreendedores de si. A operação menos governo gesta o autogoverno, e os interesses particulares dos indivíduos assujeitados por esta racionalidade política estarão consequentemente contribuindo com o interesse público e do Estado. Nesse sentido, a economia política implica a gestão das ações de governo, de seus excessos e limites, sendo possível um Estado que exerce o governo mínimo da população e do indivíduo que assume para si seu próprio controle e vigilância.

O sujeito, como nos diz Foucault (2010d), constitui-se por processos de subjetivação porque existe uma relação de forças que o assujeitam a redes contínuas de obediência, vigilância e controle e esse se subjetiva pela imposição de dizer a verdade, encontrar a verdade sobre si e sobre os outros. É, portanto, a nosso ver, nesta relação de força que vemos uma possibilidade de analisar este efeito de silêncio docente em relação à inclusão escolar, considerando que as narrativas da falta de formação e recursos e os sentimentos de impotência, tão comumente relatados há alguns anos atrás, têm agora silenciado. 
O efeito de silenciar, percebido nos professores, não diz respeito ao silêncio da palavra; mas o silêncio da palavra proferida há bem pouco tempo atrás. O silêncio aqui tem o sentido de captura, ou seja, pensar que os professores, estando capturados pela rede discursiva da inclusão, se subjetivaram pela naturalização da inclusão, tomando-a como algo dado e cristalizado em seu significado. Capturados porque agora, diante de tanto investimento na escola e em suas formações, fica o desejo de consumir a inclusão como algo que é de cada um, como algo que lhes melhora como profissionais e pessoas. Nessa rede discursiva, não há o que contestar. Resta o esforço e empreendimento que cada um precisa fazer para colocar em funcionamento a escola inclusiva, de qualidade, que é para todos e para a diversidade.

Como dizer que não estão preparados se os investimentos e programas foram e estão sendo feitos? Como não estar formado/preparado se as formações estão aí, e é claro, para quem quer empreender em si? Como questionar a inclusão se este é um princípio que borra todas as fronteiras e nos melhora como humanidade? A ironia do nosso tempo, aos moldes de como os gregos compreendiam ironia diferentemente de sarcasmo -, possibilita-nos colocar em tensão a simplificação de um enunciado que, tomado como verdade, poderia ter múltiplos significados; isso é o que o nosso tempo nos projeta. Então, sejamos irônicos!

\section{Referências}

BRASIL. Ministério da Educação. Decreto 6.571, de 17 de setembro de 2008. Dispõe sobre o atendimento educacional especializado. Brasília, DF, 2008. Disponível em: <www. planalto.gov.br/ccivil_03/_ato2007-2010/2008/Decreto/D6571.htm>. Acesso em: 03 dez. 2011.

Decreto n 7.611, de 17 de novembro de 2011. Dispõe sobre a educação especial, o atendimento educacional especializado e dá outras providências. Brasília, 2011. Disponível em: <www.planalto.gov.br/ccivil_03/_Ato2011-2014/2011/Decreto/D7611.htm>. Acesso em: 03 dez. 2011.

BRASIL. Casa Civil. Lei 11. 502 de 11 de julho de 2007. Rede nacional de formação de professores. Brasília: 2007. Disponível em: <www.planalto.gov.br/ccivil_03/_Ato20072010/2007/Lei/L11502.htm>. Acesso em: 03 dez. 2011.

BRASIL. Política Nacional de Educação Especial na Pespectiva da Educação Inclusiva. Caderno CEDES. v.28 n. 75 Campinas: maio/ag. 2008

BRASIL. Ministério da Educação. Programa de Implemantação das salas de recursos multifuncionais. Brasília, DF, 2008. Disponível em: <portal.mec.gov.br/index. php? Itemid=826\&catid=192\%3Aseesp-esducacao-especial\&id=14187\%3Aprogramade-implantacao-de-salas-de-recursos-multifuncionais-2008\&option=com content\&view=article>. Acesso em: 03 dez. 2011.

CANCLINI, N. G. Culturas Híbridas. São Paulo. EDUSP, 2008.

FONSECA, M. A. Pensar o público e o privado: Foucault e o tema das artes de governar. In: RAGO, M; VEIGA-NETO (Orgs.). Figuras de Foucault. Belo Horizonte: Autentica, 2006, p. 155-164. 
FOUCAUlT, M. A Hermenêutica do sujeito: cursos curso dado no Collège de France (1981-1982). São Paulo: Martins Fontes, 2006.

2010a.

. Ditos e Escritos IV: estratégia, poder-saber. Rio de Janeiro: Florense Universitária,

Do governo dos vivos. Curso no Collège de France, 1979-1980 (excertos). São Paulo: Achiamé, 2010c.

. História da sexualidade: a vontade de saber. Rio de Janeiro: Graal, 1988.

FOUCAULT, M. O governo de si e dos outros. São Paulo: Martins Fontes, 2010d.

. Os Anormais: cursos curso dado no Collège de France (1974-1975). São Paulo: Martins Fontes, 2010b.

GADELHA, S. Governamentalidade neoliberal, teoria do capital humano e empreendedorismo. Educação e Realidade. Porto Alegre, v. 2, n. 32, maio./ago. p. 171-186, 2009.

MENEZES, E. da C. P. de. A maquinaria escolar na produção de subjetividades para uma sociedade inclusiva. São Leopoldo: UNISINOS, 2011. Tese (Doutorado em Educação) Universidade do Vale dos Sinos, São Leopoldo, 2011.

NAUJORKS, M. I. Stress e inclusão: indicadores de stress em professores frente à inclusão de alunos com necessidades educacionais especiais. 2006. Disponível em: <www. pedagobrasil.com.br/educacaoespecial/stresseinclusao.htm>. Acesso em: 06 dez. 2011.

POSSA, L. B.; SILVEIRA, J. O. de; REVELANTE, P. Representações e imaginário docente que definem o aluno: um estudo de caso de Escolas Públicas de Santa Maria. Universidade Federal de Santa Maria, Gabinete de Projetos do Centro de Educação, Relatório de Pesquisa registro n. 020343, 31 jan. 2008.

* Leandra Boer Possa - Professora Doutora do Departamento de Educação Especial da Universidade Federal de Santa Maria. Santa Maria, Rio Grande do Sul, Brasil.

* * Maria Inês Naujorks - Professora Doutora do Departamento de Educação Especial da Universidade Federal de Santa Maria. Santa Maria, Rio Grande do Sul, Brasil.

\section{Correspondência}

Leandra Boer Possa - Universidade Federal de Santa Maria, Departamento de Educação Especial. Av.

Roraima 1000 - Cidade Universitária, Camobi

CEP: 97105-900 - Santa Maria, Rio Grande do Sul

E-mail: leandrabp@gmail.com / minau1990@gmail.com

Recebido em 23 de julho de 2012

Aprovado em 04 de março de 2013 